\title{
Categories, Morphological Features, and Slang in the Graffiti of a United States Western University
}

\author{
Manuel Breva Claramonte \\ University of Deusto \\ José Ignacio García Alonso \\ University of Deusto
}

\begin{abstract}
In this paper, we delineate some aspects of the language of graffiti from a corpus (250 pages) gathered in the Spring of 1991 at the Campus of the University of Colorado in Boulder. Our purpose is to examine the language of graffiti going beyond a simple grouping of inscriptions. This paper includes an outline of the social significance and categories of wall and desk top inscriptions. It covers the peculiar and idiosyncratic spellings observable in graffiti. It discusses abbreviations, acronyms, clippings, play on words, and rhymes. It contains an analysis of slang expressions such as compounds with head and drug terminology. Finally, it examines new derivational formations which will probably never acquire dictionary status and new meanings common among students. In sum, our corpus reveals that students are quite creative linguistically and graffiti amply illustrates how human speech changes and evolves continually.
\end{abstract}

\section{Introduction}

In this paper we delineate the language of graffiti from a corpus (250 pages) gathered in the Spring of 1991 at the campus of the University of Colorado in Boulder. The data were collected from men's latrines, classrooms, and Library buildings. The wall and desk top inscriptions have been kept in the original form and no attempt has been made to correct their spelling or punctuation marks. Studies on this topic (see Reich et al., Stocker et al., Gonos et al., Alexander, Bruner and Kelso, Melhorn and Romig, Newall, and Hentschel) concentrate on the social function of graffiti, categories, and male-female differences.

In an article on sex-graffiti in university classrooms, Nilsen (80-82) touched upon some linguistic aspects. Our purpose here is to pursue and expand the task initiated by Nilsen and examine in some detail the language of graffiti going beyond a simple grouping 
of inscriptions. This paper is divided into five parts. The first includes an outline of the social significance and categories of wall and desk top inscriptions, the second is devoted to spelling, the third covers word shortening and word play, the fourth examines slang terms and expressions, and the fifth considers new derivational formations and new meanings.

\section{Significance and categories}

Graffiti have been found in Egyptian pyramids, Greek temples, and the Roman ruins of the city of Pompeii. The tower of London contains inscriptions carrying sixteenth-century dates which were carved or scratched into the stones (cf. Fraser 258, and Melhorn and Romig 30). More recently, the walls of twentieth-century bathrooms, subways, and schools are filled with numerous inscriptions (see Reisner and Wechsler for a collection from many periods of history).

Why do people write on walls? In our corpus, graffiti artists occasionally comment on their reasons for writing their thoughts and their ideas on walls. A student from the University of Massachusetts at Amherst scribbles If it weren't for graffiti, they wouldn't wash the bathroom walls as often (see Hann and Hammerstrom 101). Other views about graffiti and graffitists appear in our corpus: Intelligent graffiti can stimulate the mind, Apparently writing on the bathroom walls instantly lowers you IQ 100 points, and My vow: to always leave the desk with more, better, funnier graffiti than when I found it. The reasons for writing on walls and the opinions of the authors of those inscriptions, however, are much broader and deeper than the previous examples would lead us to believe.

Graffiti are anonymous ways of communication without the possibility of being interrupted or rejected. By means of graffiti individuals or groups reveal their hostilities, unburden their grievances, express fantasies and frustations or declare a socially unacceptable point of view on subjects ranging from philosophy to politics, humour, religion, race relations, drugs, sports and sex. These categories may be illustrated from inscriptions in Ivy League universities collected by other graffitiologists and from our corpus: Normality distorts reality (Yale University), Nuke a republican today! (Boston University), Never trust a smiling math professor (Princeton University), Put your trust in Jesus, he will never let you down (Colorado University), Take a big bong hit, and let the chaos unfold! (Colorado University), The Bulls rule! Jordan is God (Colorado University) and College is like a virgin/hard as hell to get into/and 9 months later/you wish you never came (Colorado University) (cf. Gonos et al. 42, Haan and Hammerstrom 15, 70 and 85, and Newall 39).

It seems that graffiti are an accurate indicator of the social attitudes of a community. In addition, the topics are likely to vary according to the liberalism or conservatism of the social group in question. In trade schools, toilet wall inscriptions reflect Negro-White conflicts. Normally, racist graffiti drop when racial confrontation declines. An example of a racial line from an Eastern school is Blacks have discriminated against whites too, they never let us be the slaves (Boston College). Our University of Colorado corpus contains only a few racial insults such as All niggers should be shot and Fuck all you white people; 
this scarcity is easily understadable in that the University of Colorado is basically a white university with very few racial conflicts, in addition to being surrounded by towns with a very small black population and with no open racial conflicts (cf. Sechrest and Olson 70, Stocker et al. 363, and Haan and Hammerstrom 67). ${ }^{1}$

The University of Colorado is a liberal university and fills the pattern indicated by Melhorn and Romig (86-35), i.e. liberal universities tend to have more wall and desk top writing than conservative universities in the categories of sex, philosophy, drugs, politics, and religion. Analogously, in contrast to conservative institutions, where the topic is hardly present, antihomosexual graffiti have increased at the University of Colorado, as public tolerance of homosexuality increases. One finds $A$ good fag is a dead one and Homosexuals deserve misery and pain. They deserve AIDS! However, gays also defend themselves with such graffiti as Gay freedom now! and If you feel threatened by gays you're a wimp. No contradiction exists in the previous statements. Indeed, the more a social attitude gains in prominence, the greater the reaction from the anonymous graffitists, especially if hostility to the social attitude in question is widespread.

\section{Spelling}

In this section, we outline the peculiarities and idiosyncracies observable in the organization and distribution of letters in the words of graffiti. One encounters not only spelling errors and popular spellings, but emphatic and playful spellings as well.

2.1 Spelling errors. Orthographic errors are not uncommon in wall and desk top inscriptions. From a simple doubling of consonants, as in Shoot the biggots, or a reduction of two consonants to one, as in I hate treehugers, to more understandable inaccuracies due to the complexity of the sequence of letters as in Chemistry is beutiful and Girls are the best they are so beatiful. Sometimes, errors result from the diversity of sound implementations represented by one single grapheme. Grapheme $e$ and $i$ quite often overlap as symbols for the realization of sounds $[i:, 1,2]$. Hence the following examples, in which the letter $e$ replaces the letter $i$ and conversely: This graffite sucks-so does your spelling; Pions, In 2 months I'm out for ever; If a vegitarian eats vegitables, does a humanitarian eat humans?

Other times student graffitists have difficulties distinguishing the correct use of the apostrophe. Thus, the apostrophe occurs mistakenly in plural formations, as in Too many damn pshycho's, Ass's are big and Fuck Whitey's, or in the use of they'r for their, as in Dude, if Libya is stupid enough to stand in our way they will get they'r shit kicked again. The opposite phenomenon (i.e. the elimination of the apostrophe, where it should be present) is also common: Bigots will climb hells wall for eternity and Your a fucking pig. In the latter case, in addition to the apostrophe error, the author confuses the spelling of the personal pronoun plus the abbreviated form of are with that of the possessive because they sound the same.

2.2 Popular spellings. The difference between spelling errors and popular spellings is that the former involve unintentional mistakes while the latter are deliberate alterations of the standard written forms in order to reflect variant and conversational pronunciations. 
Thus, the particle yes has several realizations in colloquial speech. This diversity is manifested in the following graffiti:

Jesus died for his own sins ... not mine

R: are you faultless R: yep [jep]

I love Alex

$\mathrm{R}$ : yea! me too $\left[\mathrm{je}^{\mathrm{a}}\right]$

College boys are fagots

R: $\mathrm{ya}^{2}$ but smart faggots [j]

May 1991 Graduate

Yeah-Buddy!!! [jæe]

Other examples in which the shape of lexical items is altered in order to imitate colloquial speech are Brett Taryle wuz here (was) and Only Jah releave the pressah (Jahveh or Jove and pressure). Frequently, the change is meant to shock or attract the attention of the reader, as in And now boyz and girlz todayz lesson is... (a possible humorous reference to instructors' affected enunciation of final s) and $\mathrm{No} \mathrm{Nu}$ 's is good $\mathrm{Nu}$ 's (News). A deformation like $\mathrm{Nu}$ 's is very similar to those encountered in newspaper commercials (cf. sox for socks ${ }^{3}$ and Lo fat milk for Low fat milk). Therefore, it is possible that forms such as $\mathrm{Nu}$ 's may have been influenced by the field of advertising. Lastly, letters of words are dropped to indicate the deletion of sounds in colloquial or less educated speech, as in I'm me-and happy 'bout it; Hang Saddam! R: and Bush 'cause they are hipocritical butt buddies; Well I'm losin my religion, where the letters $a, b$, and $g$ are removed from about, because and losing, respectively. These deformations could be equally associated with the so-called phonetic spellings (for example, chu for you and cum bak for come back), so recurrent in the synthetic slang visible in the comic strips of many newspapers and the magazines of underground, hippie, and marginal cultural groups.

2.3 Emphatic and playful spellings. By emphatic spellings we refer to writing devices such as repetition of graphemes, punctuation marks, and lines used for the purpose of foregrounding information. A common device invoked to give prominence to syllables or words is the repetition of vowels, as in Oooh! I'm sooo angry!!; You are the cooooolest guy I know!; Help! AAAH!!! In the last phrase, besides the repetition of a vowel, there is capitalization. Likewise, strong stress may be indicated by underlining or an overabundance of exclamation marks, as in Why are finals so necessary!!!!!! Less frequent is the repetition of consonants. One graffitist wrote $C U$ students are too fucking liberal and mostly in touch with reality $R$ : ahhh, bullshit!, where $h$ is repeated three times.

In playful spellings, the author usually alters graphemes in order to amuse the reader or with a view to attracting attention. Unusual or unexpected spellings produce that effect. There exist some similarities between the phrases exhibited below and the examples mentioned earlier regarding word alterations for advertising purposes. Instances of playful spellings are: 
I can spel

I kin reed

So why can't I smoke any more weed?

Kill kweers

God bless Amerika

The grapheme changes are intentional and amusing. In CU sooks; Foock French; Fook you and Well, well my little droogies, the reader is supposed to surmise the intended word and pronunciation by analogy to the unusual pronunciation of the spelling oo in blood (cf. however, good, food, droop). Finally, in $S e^{x}=A(I) d s$, the author changes the position of a letter to above the line of writing and places $I$ in parenthesis for the purpose of making the graffiti resemble a mathematical formula.

\section{Word shortening and word play}

In this section we discuss abbreviations, acronyms, clippings, play on words, and rhymes. These features are all present in wall and desk top inscriptions.

3.1 Abbreviations. By abbreviations we understand symbols, letters, and pictures which represent whole words. Our corpus offers $+, k, n$ as the equivalents of and, as in Nuke the Middle East + turn it into a parking lot for $C U$ or Sex, drugs $\notin$ Rock-n-Roll, then lunch. The mathematical notation $=$ is also used in College =rich kids masterbating. Observe here the possible play on words between master and mastur. Some graphemes abbreviate entire words, as in $U$ fool; Women $R$ weak; What's up?-Br; Dallas, $T X$, in which $U, R, B r$ and $T X$ stand for you, are, brother and Texas, respectively. Notice that the abbreviations $B r$ and $T X$ contain more than one letter. Pictures and numerals as representations for words are observable in $\checkmark$ me 2 (love, too) and $($ is a good idea (peace).

3.2Acronyms. These formations are made up of the initial letter or letters of successive terms. Acronyms abound in English since speakers of that language are fond of their use. ${ }^{4}$ Graffiti referring to Los Angeles and New York City are L. A. Raiders suck and NYC,NY. Sometimes common expressions are shortened to their initial letters as in Your T. P. is rough and scratchy (toilet paper); UPS-we are dorks! (United Parcel Service); God, CU is a dump (Colorado University); Horny SWM seeks SWF (Single White Male, Single White Female). When the acronym is rare, it may contain an accompanying explanation as in $O Y E L=O p e n$ Your Eyes Legalize, advocationg the legalization of marihuana, or it may include a humorous response, as in the mysterious $I \vee A . K . H . o f V . W . G . B . ! S . A . V$. $R$ : you're giving away too much information. In one instance, the author replaced the standard interpretation of the acronym Fuck W. A. S. P.s (White Anglo-Saxon Protestants) by the more offensive reading "White Anglo-Saxon Pussies," which appeared underneath the acronym.

3.3 Clippings. This term refers to words that are shortened with no loss in their original semantic value. However, clippings give a colloquial or familiar flavor to one's speech, something to be expected in graffiti. One part of a word in a phrase may be dropped, as in Frat boys: write home to mummy for more money (Fraternity boys), Psycho killer 
(Psychoneurotic or psychopathic killer) or Kappa Sig is cool (Kappa Sigma), Date-Rape Pro's (Professionals), in which either the first or the second word is clipped. At times, an entire word and part of another are omitted, as in Too many God damn pshycho's (psychoneurotic or psychopathic people); Any frat that is a tease deserves to be raped (fraternity boy); No Nuke is good! (Nuclear Station).

Single words are equally clipped, as in Chem 1131 sucks $R$ : Wait till 3331 (Chemistry); Go Buffs! (Buffaloes, Local Football Team). Occasionally both the pronunciation and the spelling change as in $\Delta$ Tare HO's (whores). Ho (also hoe as in Theresa is a hoe that can't say no) has lost the initial $w$ and the vowel /o/ is realized as [ow]. ${ }^{5}$ We also found examples of front clipping where the front rather than the last part of the word is deleted as in Eat shrooms (mushrooms, a drug) and Three amigos: Coors, Commies, Coons (coons offensive for negro comes from racoon).

3.4 Play on words and rhyme. In their desire to amuse, to exhibit their wit and to be admired in their anonymity, graffitists play with words to produce funny, nonsensical, and rhythmical associations. These scribblers also display their poetic skills through simple repetition of words and elementary rhymes.

One comes upon meaningless combinations of parts of words, traditionally called spoonerisms, as in Coloversity of Univrado from University of Colorado and Barber the Conarian/Conan the Barbario from Conan the Barbarian. In a similar vein, lexical items are also transposed to produce nonsensical phrases, as in Cut your job/get a hair (cut and job are permuted) and Smoke beer R: drink pot (smoke and drink are permuted). A slogan "New World Order," coined by the Bush Administration, is altered to New World Mordor with a satirical intent. ${ }^{6}$ Other slogans have their meanings reversed Make war, not peace (from the peace movement phrase "Make peace, not war") or modified Make tea, not love (from "Make love, not war") for humorous reasons. Authors write catchy inscriptions where the catchiness depends on the phonetic similarity of words, as in Bush, the Butcher; Ballots not bullets and Frat boys Fart boys. Finally, in Define identity $R$ : id-driving instinct towards pleasure, ent-a small insect, ty-a drink, the scribbler plays with the word identity and separates several sequences of sounds $i d$, ent, and $t y$, which he ventures to define. Linguistically, it is worth noting how he identifies ent with ant, corroborating in this manner the merger that has been taking place between vowels $[\varepsilon]$ and $[æ]$ in some dialects of American English.

The kind of rhymes encountered on walls and desk tops are very simple in nature. Sometimes, one may come upon a couplet such as The bigger the nose/The longer the hose. However, most lines of poetry are based on repetition of sentence structures and on trite rhythmic correspondences of the end sounds of words.

Sleep is my deprivation

ENV D is my masturbation

Design is constipation

$R$ : Beer is my inspiration

Taxation is theft

Anarchy is chaos

Money is power 
Tuition is theft

Medical "care" is robbery

Both these graffiti repeat the same sentence structure $(\mathrm{N}+\mathrm{be}+\mathrm{N})$ and resort to a very poor rhyme, -ation the first, and the rhythmical repetition of theft, the second. A somewhat better verse, based on the same two principles, is:

I'm so tired I haven't slept a wink

I'm so tired my mind is on the blink

I'm so tired I need a drink

This verse is taken from the lyrics of a song by the Beatles, the famous pop music group.

\section{Slang terms and expressions}

This section contains an analysis of the word head, which has been the source for the formation of new compounds. Likewise, it includes graffiti with words for stupid, inept, and worthless; these words are common as qualifiers and as provocative terms of address. Lastly, we devote some space to drug terminology taken from our corpus and we exemplify those expressions with graffiti.

4.1 Head. The word head increased its productivity, as the main element of compounds, in the 1960 s and 1970 s, in connection with the drug culture. It meant a hippie or a person who drops out of society because of drug use. In Britain skinhead occurred in 1956 in the sense of a young, short-haired working-class British hoodlum. This compound extends to America to describe counter-culture shaved or bald individuals, as in the graffiti Skinheads are bald faggots. ${ }^{7}$ In Britain deadhead existed since 1841, although in America this compound has acquired the meaning of hippie, drug user or follower of the Greatful Dead, a rock group, as in Nuke the dead heads. In fact, in the United States, head, as the main element of a compound, becomes a disparaging term for person. Examples of compounds with head are plentiful in America ${ }^{8}$ and our previous and following data confirm our assumption: Does anyone know a good therapist? This war has made me a pot head (drunkard or marijuana smoker) and Nothing can stop the lonely heads from killing the kinks.

Some of the compounds are crude, rude, and provocative, and may not be recorded in ordinary dictionaries, although such expressions generally appear in slang dictionaries.' The use of these compounds is frequent among certain social groups. In I'm not an idiot $R$ : No you're a Bowhead, Bowhead suggests a girl who wears bows in her hair or who pays close attention to the way she looks. It could also be a person with a funny hairdo or a funny-shaped head. Instances of cruder formations are observable in You are a shit head (a despicable person); Ever been to a show? You ignorant dick head (a stupid person, usually a male) probably in answer to critical remarks against followers of the Greatful Dead; Love does not exist-so kill yourself and stop whining fuckhead (crazy or despicable person, asshole); I always want to remain a child $R$ : Butthead (a head like a butt, a stupid person). 
Other compounds with head may not be documented in dictionaries because they are recent, transitory creations only current among small social groups. These compounds are called deictic formations (i.e., non-lexicalized), expressions whose meaning is difficult to determine unless they appear in a context or are used within the social group in question. Examples are parrot head, $U$ duckhead, and The Omega man $R$ : who's the Omega man? $A$ parrot head could mean a person. echoing another's words, a gossip, or a woman wearing abundant make-up and jewelry. Duckhead suggests a person with a big nose, a funny-shaped head, or a stupid and unappealing person from the slang sense of duck. Omega man probably refers to a fraternity boy. The latter expression does not contain the word head, but it is included here because it illustrates our notion of deictic compound, e.i., its meaning is only possible in the context of a fraternity. ${ }^{10}$

4.2 Words for stupid, inept or worthless person. One feature of slang is that it contains scores of lexical terms with a derogatory sematic value since in those circles where slang is spoken people tend to deride their interlocutors in a joking manner. We have selected a number of graffiti with words suggesting stupidity, ineptitude or worthlessness. These nouns and adjectives enjoy wide currency among college students. The items in question are italicized.

Geologists are dorks!

All of you are a bunch of losers

ECON Geeks Prevail

CU guys are jerks

Butthole surfers

I guess I'm big shit

R: but who wants to be big shit

Hey frat assholes,

those in the KE house

Words with a positive meaning (i.e. excellent, wonderful, thrilling) are also common for people, things, and events found interesting by the young generation. These words are cool, awesome, groovy and blast. Examples from our graffiti corpus are Danielle is cool; Room for rent/awesome placela steal at \$220;ECON is a blast. It is interesting to note that some of the slang words with a positive meaning had, and still have in many cases, a negative value corresponding to their original literal or non-slang senses. Thus, awesome still means "frightening, inspiring terror"; groovy originally meant "routine, commonplace" a sense that some might now consider obsolete, and blast is still the equivalent of "a violent gust of wind or an explosion." This lexico-semantic phenomenon known by the name of antiphrasis is a quite productive process in the development of slang vocabulary. It is through this procedure that certain words already existing in a language undergo semantic changes and acquire new and contradictory meanings. Frequently this type of semantic changes is motivated by an underlying reaction on the part of the laguage user against the mainstream culture, by a desire to show irony, or by a internal urge to resort to humorous speech (cf. Rodríguez "Lenguaje y contracultura" 146).

4.3 Drug words. Graffiti with words and expressions referring to drugs are frequent in our corpus. College students are at vulnerable age due to the fact that they are away 
from their families, in addition they seek new experiences of all sorts. Some students try soft drugs such as marijuana, while a small group go into harder drugs. Our graffiti reflect this social attitude. Several lexical items for marijuana (cannabis, pot, bud, weed, herb, and sinsimelia) are documented in Smoke cannabis/be kind to your mind; Grow pot if you want to demonstrate against government policy; Where is Boulder (IN)famous Bud?-plant your seeds, share your weed; Smoking herb and partying are fucking boring anymore! and I only smoke de sinsimelia.

Other slang terms such as bong (a marijuana smoking device that cools the smoke, to smoke marijuana, a puff of marijuana), bowl (a pipe or device for smoking marijuana), joint, reefer (marijuana joint or cigarette), a hit (a marijuana puff) are also common, as in Bong till you can't bong anymore!; Bongs help the brain grow; On May 15th [the day of the last final exam] at noon, I'm going to smoke the biggest bowl of my life; Smoke 21 joints in the morning, 12 more in the afternoon; Smoke the reefer; Relax take a hit. Get off your bandwagon and live and learn a little. In the line It's better to burn out than to fade away, the expression to burn out (to become useless or tired) refers to the effects of too much marijuana smoking. In the phrase stoners unite, stoners (marijuana users) is related to I'm stoned (high on marijuana), while I'm tripping suggests being high on any kind of drug.

Other names for drugs, present in our corpus, are peyote (source of the drug mescaline), acid (for LSD), coke (for cocaine), crack (for smokable cocaine), smack (for a dose of heroin or opium), and horse (for heroin), as in Eat peyote; Drop acid/not bombs; Sex with coke; Smoke crack and die; I need a new drug R: Try smack and I'm gonna go get me some of that HOT HORSE. We complete this heading with a graffiti scribbled by a drug user who wishes to go home to his or her marijuana after a day at school:

$\begin{array}{ll}\text { Class is done } & \text { Stoned I'll sit } \\ \text { It won't be long } & \text { My mind at rest } \\ \text { home I'll run } & \text { watching shit } \\ \text { and smoke my bong } & \text { free from stress. }\end{array}$

\section{New derivational formations and new meanings}

In this section we examine new derivational formations which will probably never acquire dictionary status either due to the fact that they are erroneously formed or because they do not refer to nameworthy things or events. We also cover new meanings. This topic was touched upon in the section on the analysis of the slang word head, but we wish to expand this point further.

5.1 Jocular derivational formations. Sometimes graffitists attempt to derive new words based on their somewhat inaccurate linguistic knowledge of word components. Even if such 'neologisms' are not grammatically correct, they fulfill a jocular function. In Iraq-naphobia, the author sought to create a new word. However, -o- rather than -na-is the stemforming suffix required by English in this kind of derivations ${ }^{11}$ (cf. Germanophobia, Francophobia). In Engineering=Anthrocentric land raping? the word Anthrocentric has 
undergone an unexpected middle clipping from anthropocentric. In You are all stupid pseudo-culturists (and masturbating freshmen), the word culturist is mistakenly derived from culture by analogy with phonologist and scientist from phonology and science. Instead of pseudo-culturists, the author should have written pseudo-cultured people.

In some cases the derivations are correctly formed. In addition, these retain their novelty and humorous character. In Calvinosaurus/Penisaurus, we discern derivations from Calvin (type of dinosaur), $-o$ a stern-forming suffix plus -saurus, and from penis and -saurus, by analogy with existing forms such as tyranosaurus. In ... "Homophobe" is incorrect. That implies fear of similar things. It should be "homosexualphobe" or "fagaphobe" or "dykephobe," the author plays amateur linguist and mistakenly rejects homophobe in favor of homosexualphobe, pretending not to know that homo is a clipping from homosexual and consequently homophobe is an acceptable form for "irrational fear of homosexuals." Fagaphobe and dykephobe are the graffitist's new and disparaging formations for "fear of homosexuals" and "fear of lesbians," respectively. In Fight bimbosity! the author has derived a new term bimbosity from bimbo (a stupid woman, a clown-like person) by analogy with formations such as pomposity and monstrosity from pompous and monstrous.

5.2 New meanings. Many of the lexical items in this heading are not yet included in dictionaries in the senses given below and it is not certain whether several of these will ever be. ${ }^{12}$ Such words are not crude or obscene. The reason they have not acquired dictionary status is that they have not reached the general population as a whole. Health and environmental issues are of paramount importance among Americans, especially among college students; consequently new coinages on these topics are to be expected. In $I$ hate treehugers, it is easily discernible that treehuger means environmentalist from hugger of trees. In a similar vein, Earth muffins is an expression employed to refer to people concerned about the quality of the environment. Big muffins were food items often associated with environmentalists and earth lovers. Both expresions often suggest hippielike vegetarians obsessed with nature and conservation. A new coinage, unrelated to the environment, occurs in Get a life you fucking chud! It is unclear if chud, which is a movie creation for certain cannibalistic, humanoid, uneducated creatures, will ever become a word for general usage in the English language.

Life around schools and universities has brought about new senses to old words. One finds Boulder, granola factory of the world and Have you seen a granola who was not fat and wore shoes and did not stink? where the semantic value of granola is health and health freak, respectively, from granola (a supposedly nourishing and invigorating food staple). In Attention all Greeks: Have you no identity of your own? and Frats pay to be laid, the term Greek suggests a member of a Greek House, i.e. a fraternity or a sorority. The word frat usually is a clipping from fraternity. However, here its semantic value has undergone a shift. Indeed, it does not mean a building but the people living in it. Finally, in I like finals $R$ : You nerd, the word nerd exemplifies a semantic development which has taken place in the last several years from an umplesant and unattractive person to a dull and bookish person. This novel reading has already reached out to wider segments of the population and appears recorded in some dictionaries. 


\section{Closing remarks}

In a paper of this nature, a feeling of frustration on our part exists due to the fact that some areas of our research had to be left out. We feel that new additions would have unduly lengthened this study. Nevertheless before concluding, it would be appropriate to touch upon the syntactic features of graffiti. Several examples reveal that leveling takes place in the third person singular of the present tense Only $\mathrm{Ja}$ releave the pressah; This is the "John Wayne" toilet paper: Rough and tough and don't take shit and Is you is or is ain't my baby?, in which releave has no final $-s$, don't supplants the standard doesn't and is occurs instead of are. Note that ain't acts as the equivalent of the negative particle not in the last phrase. At times, inscriptions are written in telegraphic style, offering unusual deletions. Deletion of subject occurs in Can't think of anything to write (I), deletion of conjunction and subject in Don't like what our govt does. Get the fuck out of it (If you). Deletion of subject and auxiliary verb happens in Know any nymphos? (Do you); Ever been to a show? You ignorant dick head (Have you) and Brothers, gonna work it out (I'm, you're or we're). Deletion of verbs appears in Frat boys Fart boys (are) and LSD peace through Chemistry (means).

Briefly stated, in this paper we presented a few ideas about the social significance and the various categories of graffiti and we ventured to describe some of the linguistic features of graffiti. In the spelling section, we listed errors stemming from simple negligence, purposeful alterations of forms which reflected popular pronunciations, uncommon combinations of letters with a view to surprising or to amusing the reader, and the repetition of graphemes for emphatic reasons. Another section covered abbreviations or the utilization of symbols, letters and pictures to represent words, acronyms or lexical items formed with the initial letters of successive terms, word play including transposition of syllables, transposition of entire lexical items and modification of widely known slogans, and elementary rhymes. Graffitists sometimes resort to word shortening, word play and rhymes in their desire to entertain, to shock with nonsensical expressions and to show their wit as poets. Another section focused on slang terms and expressions. Here, the word head (slang for person) in the formation of compounds in the last twenty years was examined. This section also contained frequently used slang words for stupid and inept and their antonyms, as well as vocabulary involving the use of marijuana and other drugs. Finally, the last section was devoted to new derivational formations and new meanings. We perceived that scribblers play amateur linguists and are not always successful in combining morphemes into words. Graffiti are an excellent source to instantiate the birth of informal meanings resulting from new coinages or from semantic shifts in the value of old words.

In sum, our corpus reveals that students (extensible to other social groups) are quite creative linguistically. A number of the recent word formations documented in this paper has acquired dictionary status in slang dictionaries and certainly a few will be introduced into standard dictionaries in the future. Graffiti amply illustrate the power of linguistic creativity and show how human speech changes and evolves continually. 


\section{Notes}

1. For an informative and interesting article on racial slurs, consult Blake. For early attempts in this century to collect folk epigraphy in the United States, see Read.

2. The form ya generally occurs as the weak form of the personal pronoun you as in Did ya here the one about the vacuum? It sucks. Another popular variant chw is observable in Yes, baby, go down on me, don't chw know. Popular spellings are a time-honored literary tradition in US writing from Mark Twain's Huckleberry Finn (1885) onwards.

3. Additional inscriptions found on walls and desk tops are Communism SUX, Filthy MacNasty SUX and CSUcks (i.e. Colorado State University sucks).

4. Eble (31-33) provides a list of acronyms among college students. For example, M. L. A. (passionate kissing, from massive lip action), TAN (aggressively masculine, from tough as nails), N. B. D. (something unimportant, from no big deal) and O. O. C. (drunk, high on drugs, or acting crazy, from out of control). On the topic of abbreviations and student slang, see also Rodriguez ("Abbreviations" 41).

5. Ho comes from Black speech. It appears to have been introduced into the general public by Black comedian Eddie Murphy. Vowel /o/ is pronounced [ow] in parts of the South (cf. dog and four pronounced [dowg] and [fowr]). This phenomenon is known as Southern breaking. Other instances are cloth, thought, north, and bought.

6. This word could also be a possible reference to Mordor from J. R. R. Tolkien's Lord of the Rings. In this novel, Mordor refers to a land of darkness and evil which threatened the world.

7. In Spanish the word cabeza is not as prolific as its English counterpart for the formation of new expressions. One finds cabeza rapada as a calque or direct translation of skinhead, cabeza chorlito, cabeza loca, cabeza de alcornoque, and cabezón.

8. Fathead, thickhead, airhead (stupid person), acidhead (user of LSD), crackhead (user of crack), smackhead (user of heroin) and budhead (beerdrinker, from Budweiser, a popular beer brandname).

9. For instance, Harrap's Slang: French-English Dictionary, NTC's Dictionary of American Slang and Slang U: The Official Dictionary of College Slang.

10. The word bag (originally an ugly female) has undergone the same development as head. Bag is now a derogatory term for male and female as in the following graffiti. Hairbags suck dick!; Get a life you fucking conformist shitbag; Die Jew R: $O$. K. Nazi low life dickless scumbag. The basic semantic value of bag is that of an unclean, worthless person. In addition to hairbag, shitbag, and scumbag, one encounters ratbag and fleabag with the same idea of dirty person. In ragbag, fagbag, and skagbag, premodifiers rag, fag, and skag add the feature badly dressed, homosexual and prostitute, respectively.

11. It is also probable that Iraq-na-phobia is a pun on Arachnaphobia or Aracnaphobia, the title of a popular movie about the fear of spiders.

12. For instance, Webster's Ninth New Collegiate Dictionary.

\section{Works Cited}

Alexander, Bob. "Male and Female Rest Room Graffiti." Maledicta: The Journal of Verbal Aggression 2 (1978): 42-59.

Blake, C. Fred. "Graffiti and Racial Insults: The Archaeology of Ethnic Relations in Hawaii." Modern Material of Culture: The Archaeology of US (Studies in Archaeology). Ed. Richard 
A. Gould and Michael B. Schiffer. New York: Academic Press, 1981. 87-99. Bruner, Edward M. and Jane Paige Kelso. "Gender Differences in Graffiti: A Semiotic Perspective." Women's Studies International Quarterly 3 (1980): 239-252.

Eble, Connie. College Slang 101. Georgetown: Spectacle Lane Press, 1989.

Fraser, Bruce. "Meta-Graffiti." Maledicta: The International Journal of Verbal Aggression 4 (1980): 258-261.

Gonos, George, Virginia Mulkern and Nicholas Poushinsky. “Anonymous Expressions: A Structural View of Graffiti."Journal of American Folklore 89 (1976): 40-48.

Haan, Marina N. and Richard B. Hammerstrom. Graffiti in the Ivy League (and Thereabouts). New York: Warner Books, 1981.

Harrap's Slang: French-English Dictionary: Dictionnaire Anglais-Français. 1984. Georgette A. Marks and Charles B. Johnson. Completely revised and edited by Jane Pratt. London: Harrap, 1987.

Hentschel, Elke. "Women's Graffiti." Multilingua: Journal of Interlanguage Communication 6 (1987): 287-308.

Melhorn, J. Jack and Ralph J. Romig. "Rest Room Graffiti: A Discriptive Study." Emporia State Research Studies 34 (1985): 29-45.

Newall, Venetia. "The Moving Spray Can: A Collection of Some Contemporary English Graffiti." Maledicta: The International Journal of Verbal Aggression 9 (1986-1987): $39-47$.

Nilsen, Don L. F. "Sigma Epsilon XI: Sex in the Typical University Classroom." Maledicta: The International Journal of Verbal Aggression 5 (1981): 79-91.

NTC's Dictionary of American Slang and Colloquial Expressions. 1989. Edited by Richard A. Spears. Lincolnwood: National Textbook Company, 1991.

Read, Allan Walker. Classic American Graffiti. Lexical Evidence from Folk Epigraphy in Western North America: A Glossarial Study of the Low Element in the English Vocabulary. 1935. Waukesha, Wisconsin: Maledicta Press, 1977.

Reich, Wendy, Rosalie Buss, Ellen Fein, and Terry Kurtz. "Notes on Women Graffiti." Journal of American Folklore 90 (1977): 188-191.

Reisner, Robert and Lorraine Wechsler. Encyclopedia of Graffiti. New York: Macmillan, 1974.

Rodríguez González, Félix. "Lenguaje y contracultura: Anatomía de una generación." Comunicación y lenguaje juvenil. Madrid: Fundamentos, 1987.

. "Abbreviations and American Slang." English Today 31 (1992): 39-44.

Sechrest, Lee and A. Kenneth Olson. "Graffiti in Four Types of Institutions of Higher Education." The Journal of Sex Research 7 (1971): 62-71.

Slang U: The Official Dictionary of College Slang. Comp. Pamela Munro et al. New York: Harmony Books, 1991.

Stocker, Terrance L., Linda W. Dutcher, Stephen H. Hargrove, and Edwin A Cook. "Social Analysis of Graffiti." Journal of American Folklore 85 (1972): 356-366.

Webster's Ninth New Collegiate Dictionary. Springfield, Massachusetts: Merrian-Webster Publishers, 1990. 